\section{Quadruply bonded dimolybdenum complexes with highly unusual geometries and vacant coordination sites $\dagger$}

\author{
Mario Carrasco, ${ }^{a}$ Michelle Faust,${ }^{b}$ Riccardo Peloso, ${ }^{a}$ Amor Rodríguez, ${ }^{a}$ \\ Joaquín López-Serrano, ${ }^{a}$ Eleuterio Álvarez, ${ }^{a}$ Celia Maya, ${ }^{a}$ Philip P. Power ${ }^{* b}$ and \\ Ernesto Carmona $* a$
}

Received 17th January 2012, Accepted 25th February 2012

DOI: $10.1039 / \mathrm{c} 2 \mathrm{cc} 30394 \mathrm{a}$

New quadruply bonded dimolybdenum complexes of the terphenyl ligand $\mathrm{Ar}^{\mathrm{Xyl} l_{2}}\left(\mathrm{Ar}^{\mathrm{Xyl_{2 }}}=\mathrm{C}_{6} \mathrm{H}_{3}-2,6-\left(\mathrm{C}_{6} \mathrm{H}_{3}-2,6-\mathrm{Me}_{2}\right)_{2}\right)$ have been prepared and structurally characterized. The steric hindrance exerted by the $\mathrm{Ar}^{\mathrm{Xyl}_{2}}$ groups causes the Mo atoms to feature unsaturated four-coordinate structures and a formal fourteenelectron count.

The recognition of the first metal-metal quadruple bond in the $\left[\mathrm{Re}_{2} \mathrm{Cl}_{8}\right]^{2-}$ anion in 1964 marked the beginning of a new era of chemistry that experienced a spectacular growth in the following decades with the synthesis and characterization of numerous complexes containing multiple bonds between transition metal atoms. ${ }^{1}$ Despite the profound knowledge acquired in the time that has elapsed, this fascinating field of chemistry is still providing new, surprising, and highly interesting results. ${ }^{1,2}$ In this sense, the use of sterically encumbered ligands to stabilize lowcoordinated metal complexes has allowed the isolation of species of unusual structural properties, including into this category the first complexes containing a quintuple metal-metal bond. ${ }^{3-8}$

Quadruply bonded dimolybdenum compounds have been extensively studied and consequently a plethora of structural and spectroscopic data are available. ${ }^{1,2}$ The vast majority of these complexes exhibit a paddlewheel structure in which the coordination number for the molybdenum centers is five (considering the metal-metal bond). Recently Tsai and co-workers have isolated the first three-coordinate, quadruply bonded $\mathrm{Mo}_{2}$ dimers using bulky amido ligands. ${ }^{9}$

Bulky terphenyl ligands have been broadly used to suppress possible side reactions in low-coordinated complexes, and to provide enhanced stability in a wide range of metal-metal bonded compounds. ${ }^{10} \mathrm{We}$ now report that choosing compounds

\footnotetext{
${ }^{a}$ Instituto de Investigaciones Quimicas (IIQ), Departamento de Quimica Inorgánica, Universidad de Sevilla-Consejo Superior de Investigaciones Cientificas, Avenida Américo Vespucio 49,

41092 Sevilla, Spain.E-mail: guzman@us.es; Fax: + 34-954460565

${ }^{b}$ Department of Chemistry, University of California,

One Shields Avenue, Davis, California 95616, USA.

E-mail:pppower@ucdavis.edu

$\dagger$ Electronic supplementary information (ESI) available: Experimental procedures and characterization data for all new compounds described herein along with CIF files for 2 and 3. CCDC 862529 and 862530. For ESI and crystallographic data in CIF or other electronic format see DOI: $10.1039 / \mathrm{c} 2 \mathrm{cc} 30394 \mathrm{a}$
}

$\left[\mathrm{Mo}_{2}\left(\mathrm{O}_{2} \mathrm{CR}\right)_{4}\right](\mathrm{R}=\mathrm{Me}, \mathbf{1 a} ; \mathrm{H}, \mathbf{1 b})$ as metal precursors, the mono- and bis-terphenyl derivatives $\left.\left[\mathrm{Mo}_{2}\left(\mathrm{Ar}^{\mathrm{Xyl}}\right)_{2}\right)\left(\mathrm{O}_{2} \mathrm{CMe}\right)_{3}\right], \mathbf{2}$, and $\left[\mathrm{Mo}_{2}\left(\mathrm{Ar}^{\mathrm{Xyl}}\right)_{2}\left(\mathrm{O}_{2} \mathrm{CH}\right)_{2}\right], 3$, respectively, can be isolated and characterized. Somewhat surprisingly, information on well-characterized dimeric alkyl or aryl Mo(II) compounds is scarce. ${ }^{1,11}$ Moreover, the steric pressure exerted by the bulky $\mathrm{Ar}^{\mathrm{Xyl}}{ }_{2}$ group allows the observation in $\mathbf{2}$ and $\mathbf{3}$ of very unusual four-coordinate, 14-electron structures derived from a square pyramidal geometry that has an empty basal site. These compounds could be useful precursors for so far unknown low-coordinate second row diorganometal(II) species.

Reactions of $\left[\mathrm{Mo}_{2}\left(\mathrm{O}_{2} \mathrm{CR}\right)_{4}\right]$ compounds with various alkylating reagents to give quadruply bonded dimolybdenum alkyl complexes stabilized by phosphine ligands were reported years ago by Wilkinson, Andersen, and their co-workers. ${ }^{11}$ In our hands, use of the bulky terphenyl $\mathrm{Ar}^{\mathrm{Xyl}_{2}}$ permits incorporation of one or two $\mathrm{Ar}^{\mathrm{Xyl}_{2}}$ units, depending on the nature of the carboxylate, $\mathrm{RCO}_{2}{ }^{-}$group. Thus, treatment of the acetate dimer 1a with 1 equivalent of the lithium terphenyl $\mathrm{LiAr}^{\mathrm{Xyl}_{2}}$ occurred with substitution of one carboxylate ligand by the $\mathrm{Ar}^{\mathrm{Xyl}_{2}}$ group and formation of the mono(terphenyl) derivative 2 (Scheme 1).

The new compound was isolated as a moisture and oxygen sensitive, deep-red crystalline solid, in over $65 \%$ yield. Spectroscopic properties (see ESI $\dagger$ ) are in agreement with the proposed formulation. The two flanking 2,6- $\mathrm{Me}_{2} \mathrm{C}_{6} \mathrm{H}_{3}$ aryl units of the $\mathrm{Ar}^{\mathrm{Xyl}} \mathrm{l}_{2}$ ligand in $\mathbf{2}$ are inequivalent at room temperature and their methyl groups give well-defined ${ }^{1} \mathrm{H}$ resonances at 2.18 and $2.35 \mathrm{ppm}$ (each integrating for 6H). NOESY NMR measurements reveal that they undergo exchange and indeed, heating toluene- $d_{8}$ solutions of $\mathbf{2}$ causes broadening of these signals until they merge into a single resonance at temperatures over $80^{\circ} \mathrm{C}$.

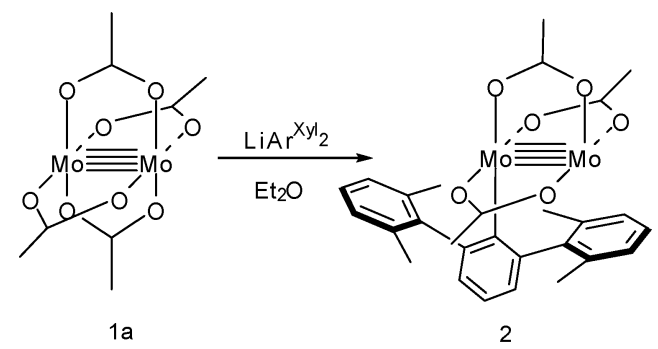

Scheme 1 Synthesis of the mono(terphenyl) derivative, 2. 


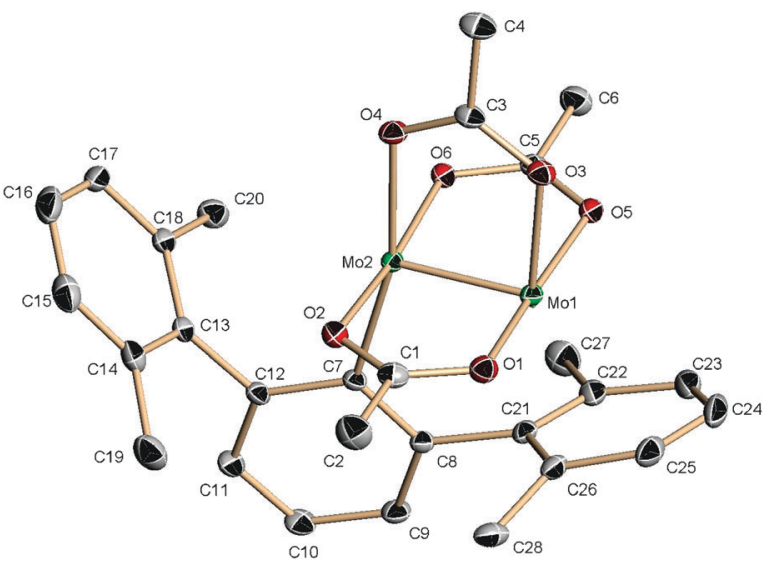

Fig. 1 Molecular structure of 2 (30\% probability ellipsoids). Selected bond lengths $(\AA)$ and angles $\left({ }^{\circ}\right)$ : $\operatorname{Mo}(1)-\operatorname{Mo}(2), 2.086(1)$; $\operatorname{Mo}(1)-C(7)$, 2.192(1); $\mathrm{Mo}(1)-\mathrm{O}(1), 2.101(1) ; \mathrm{Mo}(1)-\mathrm{O}(2), 2.099(1) ; \mathrm{Mo}(1)-\mathrm{O}(3)$, 2.088(1); $\mathrm{Mo}(2)-\mathrm{O}(4), 2.161(1) ; \mathrm{Mo}(1)-\mathrm{O}(5), 2.087$ (1); $\mathrm{Mo}(2)-\mathrm{O}(6)$, 2.117(1); C(7)-Mo(2)-Mo(1) 103.22(3).

This dynamic behavior can be associated with hindered rotation of the terphenyl ligand around the Mo-C bond.

$\mathrm{X}$-Ray studies (Fig. 1 and ESI $\dagger$ ), demonstrated the existence in compound 2 of a central $\mathrm{Mo}_{2}{ }^{4+}$ unit with different coordination environments for the two Mo atoms. $\mathrm{Mo}(2)$ is bonded to three carboxylate oxygen atoms (average $\mathrm{Mo}-\mathrm{O}=2.13 \AA$ ), the terphenyl carbon, $\mathrm{C}(7)$, and the other molybdenum atom, $\mathrm{Mo}(1)$, in a distorted square-pyramidal geometry. The Mo(2) atom is $c a$. $0.17 \AA$ out of the mean plane of the surrounding $\mathrm{O}$ and $\mathrm{C}$ donor atoms, whereas $\mathrm{Mo}(1)$ is at the vertex of the pyramid, forming a metal-metal bond with a length of 2.086(1) $\AA$, which can be categorized as a typical quadruple bond. ${ }^{12}$ The $\mathrm{Mo}(2)-\mathrm{C}(7)$ distance to the terphenyl ligand of 2.192(1) $\AA$ is only ca. $0.06 \AA$ longer than corresponding $\mathrm{Cr}-\mathrm{C}$ distances in the quintuply bonded dichromium compounds $\mathrm{Cr}_{2} \mathrm{Ar}_{2}{ }_{2}\left(\right.$ ca. $2.13 \AA$ ). ${ }^{3}$

Molybdenum atom $\mathrm{Mo}(1)$ features instead an unsaturated coordination environment, which, once more, may be viewed as distorted square-pyramidal, but with one of the basal sites unoccupied. Apart from the other metal atom, Mo(1) is only bonded to three carboxylate oxygen atoms, with an average Mo-O distance of $2.09 \AA$. It is tempting to view one of the flanking aryl rings as occupying the fifth coordination site, similar to the weak secondary interactions observed in Power's $\mathrm{Cr}_{2} \mathrm{Ar}_{2}{ }_{2}$ complexes. ${ }^{3,6 c, 6 g}$ But the shortest $\mathrm{Mo}-\mathrm{C}$ distance to this ring $(\mathrm{Mo}(1) \mathrm{C}(26)$ in Fig. 1) is of 2.571(1) $\AA$, too long to be considered as representing significantly a sharing of electron density. This distance is in fact about $0.38 \AA$ longer than the $\mathrm{Mo}(2)-\mathrm{C}(7)$ sigma bond, whereas in $\mathrm{Cr}_{2} \mathrm{Ar}_{2}^{\prime}$ species the difference between the sigma bond and the weak secondary interaction is ca. $0.16 \AA$. Thus, the role of this flanking aryl ring seems to be protective, rather than coordinating. It shields the unsaturated molybdenum atom against interactions with the surroundings, being forced into the position it adopts by the nature of the terphenyl ligand and its characteristic spatial extent.

Somewhat surprisingly, treatment of $\mathbf{1 a}$ or $\mathbf{2}$ with an excess of $\mathrm{LiAr}^{\mathrm{Xyl}_{2}}$ did not lead to replacement of the acetate trans to the terphenyl, even after prolonged refluxing of the reaction mixture in THF. In view of this result, the formate $\left[\mathrm{Mo}_{2}\left(\mathrm{O}_{2} \mathrm{CH}\right)_{4}\right], \mathbf{1 b}$, was used. The formate ligand is better a
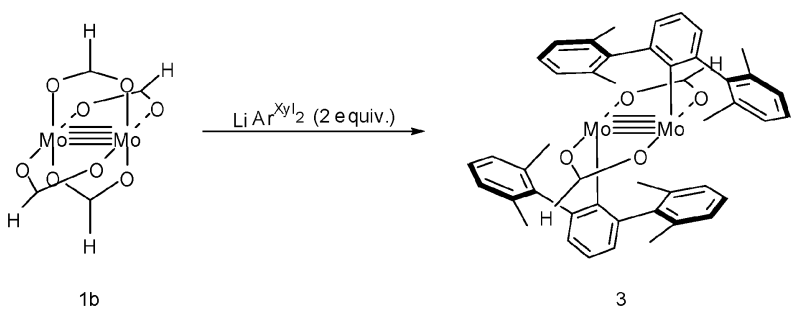

Scheme 2 Synthesis of the bis(terphenyl) derivative, 3.

leaving group than acetate (corresponding $\mathrm{p} K_{\mathrm{a}}$ values for the conjugated acids are $3.75, \mathrm{R}=\mathrm{H}$ and $4.75, \mathrm{R}=\mathrm{Me})$. In addition, formate is less sterically demanding than acetate.

As shown in Scheme 2, reaction of $\mathbf{1 b}$ with 2 equivalents of $\mathrm{LiAr}{ }^{\mathrm{Xyl}}{ }_{2}$ gave the desired $\left[\mathrm{Mo}_{2}\left(\mathrm{Ar}^{\mathrm{Xyl}}\right)_{2}\left(\mathrm{O}_{2} \mathrm{CH}\right)_{2}\right]$ dimer 3, which was isolated as a very air sensitive red crystalline material. ${ }^{1} \mathrm{H}$ and ${ }^{13} \mathrm{C}\left\{{ }^{1} \mathrm{H}\right\}$ NMR spectroscopic studies, performed in $\mathrm{C}_{6} \mathrm{D}_{6}$, confirmed the incorporation of two terphenyl ligands and formation of dimeric molecules with $C_{2 \mathrm{~h}}$ symmetry. Thus a deshielded singlet was recorded at $8.97 \mathrm{ppm}$ (relative intensity $2 \mathrm{H}$ ) for the formate protons, along with two other singlets with $\delta 1.94$ and 2.17, each integrating for $12 \mathrm{H}$, attributable to the Me groups of the $\mathrm{Ar}^{\mathrm{Xyl}_{2}}$ ligands.

This compound was also characterized by X-ray crystallography (Fig. 2). Each metal atom is bonded to the other, with a separation of ca. $2.09 \AA$, and is surrounded by two oxygen atoms from the carboxylate ligands, with an average $\mathrm{Mo}-\mathrm{O}$ distance of $2.11 \AA$, and by the carbon atom of the central aryl ring of the terphenyl ligand. In compound $\mathbf{3}$, the $\mathrm{Mo}(1)-\mathrm{C}(1)$ bond length of 2.187(3) $\AA$ is identical, within experimental error, to the corresponding distance in the mono(terphenyl) species 2. However, for each molybdenum atom the shortest contact with the flanking aryl ring $\left(\mathrm{Mo}\left(1^{\prime}\right)-\mathrm{C}(15)\right.$ in Fig. 2), i.e. the supposed secondary interaction, at $2.78 \AA$, is ca. $0.21 \AA$ longer than in compound 2 and almost $0.59 \AA$ longer than the $\mathrm{Mo}-\mathrm{C}_{\text {aryl }}$ sigma bonds within the molecules of $\mathbf{3}$. This supports the notion that there is very little (if any) covalent interaction between these units. Therefore, in complex 3 each Mo center exhibits an unsaturated structure, with a formal 14-electron count. The coordination geometry approaches a distorted square-pyramidal geometry, in which the basal site trans to the aryl carbon is empty, as a consequence of the occupancy of

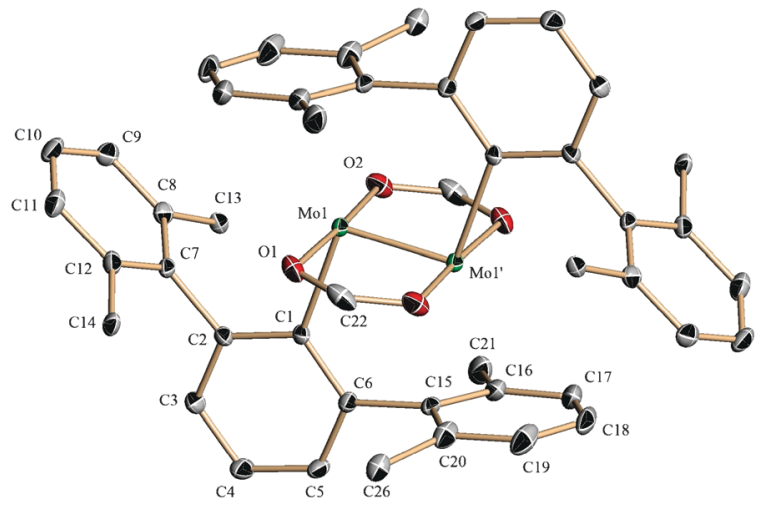

Fig. 2 Molecular structure of 3. Selected bond lengths $(\AA)$ and angles $\left({ }^{\circ}\right)$ : $\mathrm{Mo}(1)-\mathrm{Mo}(1)^{\prime}, 2.095(1) ; \mathrm{Mo}(1)-\mathrm{C}(1), 2.187(3) ; \mathrm{Mo}(1)-\mathrm{O}(1), 2.106(3)$; $\mathrm{Mo}(1)-\mathrm{O}(2), 2.110(3) ; \mathrm{C}(1)-\mathrm{Mo}(1)-\mathrm{Mo}\left(1^{\prime}\right)$ 99.24(9); C(1')-Mo(1')-C(15) $170.8(1)$. 
this region of the space by a flanking aryl ring of the terphenyl ligand bound to the other molybdenum atom.

To gain a deeper insight into the nature of the bonding in $\mathbf{3}$ computational studies were performed. Density Functional Theory (DFT) calculations at the M $06^{13}$ level afforded a gas phase geometry for $\mathbf{3}$ in very good agreement with the X-ray data. The shortest calculated distance between the Mo atoms and the flanking aryls is $2.79 \AA$ but, interestingly, when the $\mathrm{Ar}^{\mathrm{xyl}}$ terphenyl ligand is replaced by 2-biphenyl (3calc) (see ESI $\dagger$ ), the shortest Mo-phenyl contact becomes $2.57 \AA$, which is almost identical to the X-ray data for $\mathbf{2}$. This suggests that steric interactions in $\mathbf{3}$ play a role in elongating the Mo-Aryl contact. The nature of the secondary interaction was addressed by NBO analysis ${ }^{14}$ and analysis of the calculated electron density of $\mathbf{3}$ within the Quantum Theory of Atoms in Molecules formalism. ${ }^{15,16}$ Bond Critical Points (BCPs) were located connecting the Mo atoms and the ipso carbons of the flanking aryls. The charge density values at these $\mathrm{BCPs}\left[\rho\left(\boldsymbol{r}_{\mathrm{c}}\right)\right]$ are low ( 0.025 au compared to 0.103 au for the Mo-C sigma bonds BCPs). The positive values of the laplacian of the electron density at these critical points $\left[\nabla^{2} \rho\left(\boldsymbol{r}_{\mathbf{c}}\right)\right]$ indicate closed shell (ionic) interactions. ${ }^{17-19} \mathrm{An}$ analogous analysis for 3calc gives almost identical results for the two BCPs that connect each Mo with one of the ortho carbons of the corresponding flanking phenyls. The Wiberg Bond Orders (WBOs) for the Mo-Aryl interactions are below 0.3 for $\mathbf{3}$ (the largest contribution, 0.08 , corresponding to the $\mathrm{Mo}-\mathrm{C}_{i p s o}$ interactions), while for 3calc the corresponding WBOs increase to 0.31 (with the largest contribution corresponding now to the $\mathrm{Mo}-\mathrm{C}_{\text {ortho }}$ interactions, 0.15). These results are consistent with weak, primarily ionic in nature, interactions between the Mo atoms of $\mathbf{3}$ (and 2) and the flanking aryls of the terphenyl ligands.

In summary, through electronic and steric modification of the carboxylate platform of dimolybdenum tetracarboxylate dimers, $\left[\mathrm{Mo}_{2}\left(\mathrm{O}_{2} \mathrm{CR}\right)_{4}\right]$, and with the use of bulky terphenyl ligands, we have developed a useful synthetic strategy that allows access to quadruply bonded dimolybdenum complexes of terphenyl ligands. A bis(terphenyl) bis(formate) compound in which each molybdenum atom possesses an unsaturated four-coordinate structure and a formal fourteen-electron count has been prepared.

Financial support (FEDER contribution and Subprogramas Juan de la Cierva and Ramon y Cajal) from the Spanish Ministry of Science and Innovation (Projects CTQ2010-15833 and Consolider-Ingenio 2010 CSD2007-00006) and the Junta de Andalucía (Grant FQM-119 and Project P09-FQM-5117) is gratefully acknowledged. M. C. thanks the Spanish Ministry of Education for a research grant (AP-4193). M. F. and P. P. P. thank the U. S. National Science Foundation (CHE-0948417) for financial support. The use of computational facilities of the Consejo Superior de Investigaciones Científicas (Cluster Trueno) and the Center of Supercomputing of Galicia (CESGA) are thankfully acknowledged.

\section{Notes and references}

1 (a) Multiple Bonds Between Metal Atoms, ed. F. A. Cotton, C. A. Murillo and R. A. Walton, Springer Science and Business Media, Inc, New York, 3rd edn, 2005.

2 (a) M. H. Chisholm, Proc. Natl. Acad. Sci. U. S. A., 2007, 104, 2563; (b) M. H. Chisholm and B. J. Lear, Chem. Soc. Rev., $2011, \mathbf{4 0}, 5254$

3 (a) T. Nguyen, A. D. Sutton, S. Brynda, J. C. Fettinger, G. J. Long and P. P. Power, Science, 2005, 310, 844; $(b)$ R. Wolf, C. Ni, T. Nguyen, M. Brynda, G. J. Long, A. D. Sutton, R. C. Fischer, J. C. Fettinger, M. Hellman, L. Pu and P. P. Power, Inorg. Chem., 2007, 46, 11277

4 (a) Y.-C. Tsai, C.-W. Hsu, J.-S. K. Yu, G.-H. Lee, Y. Wang and T.-S. Kuo, Angew. Chem., Int. Ed., 2008, 47, 7250; (b) C.-W. Hsu, J.-S. K. Yu, C.-H. Yen, G.-H. Lee, Y. Wang and Y.-C. Tsai, Angew. Chem., Int. Ed., 2008, 47, 9933.

5 (a) A. Noor, F. R. Wagner and R. Kempe, Angew. Chem., Int. Ed., 2008, 47, 7246; (b) A. Noor, G. Glatz, R. Müller, M. Kaupp, S. Demeshko and R. Kempe, Z. Anorg. Allg. Chem., 2009, 635, 1149; (c) A. Noor, G. Glatz, R. Müller, M. Kaupp, S. Demeshko and R. Kempe, Nat. Chem., 2009, 1, 322; (d) F. R. Wagner, A. Noor and R. Kempe, Nat. Chem., 2009, $1,529$.

6 (a) G. Frenking, Science, 2005, 310, 796; (b) U. Radius and F. Breher, Angew. Chem., Int. Ed., 2006, 45, 3006; (c) M. Brynda, L. Gagliardi, P.-O. Widmark, P. P. Power and B. O. Roos, Angew. Chem., Int. Ed., 2006, 45, 3804; (d) C. R. Landis and F. Weinhold, J. Am. Chem. Soc., 2006, 128, 7335; (e) B. O. Roos, A. C. Borin and L. Gagliardi, Angew. Chem., Int. Ed., 2007, 46, 1469; (f) G. Merino, K. J. Donald, J. S. D'Acchioli and R. Hoffmann, J. Am. Chem. Soc., 2007, 129, 15295; $(g)$ G. La Macchia, L. Gagliardi, P. P. Power and M. Brynda, J. Am. Chem. Soc., 2008, 130, 5104; (h) M. Brynda, L. Gagliardi and B. O. Roos, Chem. Phys. Lett., 2009, 471, 1; (i) G. La Macchia, G. Li Manni, T. K. Todorova, M. Brynda, F. Aquilante, B. O. Roos and L. Gagliardi, Inorg. Chem., 2010, 49, 5216.

7 Y.-C. Tsai, H.-Z. Chen, C.-C. Chang, J.-S. K. Yu, G.-H. Lee, Y. Wang and T.-S. Kuo, J. Am. Chem. Soc., 2009, 131, 12534.

8 K. A. Kreisel, G. P. A. Yap, O. Dmitrenko, C. R. Landis and K. H. Theopold, J. Am. Chem. Soc., 2007, 129, 14162.

9 Y.-C. Tsai, Y.-M. Lin, J.-S. K. Yu and J.-K. Hwang, J. Am. Chem. Soc., 2006, 128, 13980.

10 (a) Z. Zhu, M. Brynda, R. J. Wright, R. C. Fischer, W. A. Merrill, E. Rivard, R. Wolf, J. C. Fettinger, M. M. Olmstead and P. P. Power, J. Am. Chem. Soc., 2007, 129, 10847; (b) E. Rivard and P. P. Power, Inorg. Chem., 2007, 46, 10047.

11 (a) R. A. Andersen, R. A. Jones and G. Wilkinson, J. Chem. Soc., Dalton Trans., 1978, 446; (b) G. S. Girolami, V. V. Mainz, R. A. Andersen, S. H. Vollmer and V. W. Day, J. Am. Chem. Soc., 1981, 103, 3953; (c) G. S. Girolami, V. V. Mainz and R. A. Andersen, J. Am. Chem. Soc., 1982, 104, 2041.

12 F. A. Cotton, L. M. Daniels, E. A. Hillard and C. A. Murillo, Inorg. Chem., 2002, 41, 2466.

13 Y. Zhao and D. Truhlar, Theor. Chim. Acta, 2008, 120, 215.

14 A. E. Reed, L. A. Curtis and F. Weinhold, Chem. Rev., 1988, 88, 899.

15 R. F. Bader, Atom in Molecules: A Quantum Theory, Oxford University Press, Oxford, UK, 1995.

16 R. F. W. Bader, Chem. Rev., 1991, 91, 893.

17 A. Sierraalta, Chem. Phys. Lett., 1994, 227, 557.

18 J. Saßmannshausen, A. Track and T. A. D. S. Dias, Eur. J. Inorg. Chem., 2007, 2327.

19 W. Scherer and G. S. McGrady, Angew. Chem., Int. Ed., 2004, 43, 1782 . 